\title{
Fluorescent Probes that Stain Living Nerve Terminals
}

\author{
Lorenzo Magrassi, Dale Purves, and Jeff W. Lichtman \\ Department of Anatomy and Neurobiology, Washington University School of Medicine, St. Louis, Missouri 63110
}

\begin{abstract}
We have evaluated the efficacy of 18 cationic mitochondrial dyes that, as a class, show some ability to stain living nerve terminals. Several of these agents provide excellent staining of neuromuscular junctions in a wide range of species. More detailed studies of the most effective of these dyes4-(4-diethylaminostyryl)- $\mathrm{N}$-methylpyridinium iodide (4-Di-2ASP)-indicate that it has no lasting effect on the structure or function of motor nerve terminals. As demonstrated in the accompanying paper (Lichtman et al., 1987; see also Lichtman et al., 1986), 4-Di-2-ASP can therefore be used to follow the configuration of identified motor terminals over arbitrarily long intervals.
\end{abstract}

A number of fundamental questions about the development and stability of synapses might be answered by repeated observation of nerve terminals in living animals at intervals of weeks or months. Two general approaches to this problem are plausible: the use of optical methods that enhance contrast, and vital staining. Optical techniques such as differential interference contrast have been used in vitro (see, for example, McMahan and Kuffler, 1971), but this approach requircs thin preparations that can be transilluminated. Similarly, most vital stains have serious limitations. Only a few reagents specifically label axon terminals in living preparations, and many of these are toxic. This is particularly true of dyes visualized by light absorbance, since these reagents must be used in relatively high concentrations. For example, the best known vital dye-methylene blue-stains nerve terminals quite effectively (Polyak, 1941; Coers and Woolf, 1959). However, anatomical and physiological signs of damage at nerve terminals are apparent within minutes of application (see, for example, Purves and Lichtman, 1987).

An alternative approach is to use dyes that fluoresce; the major advantage of such agents is that they can be visualized at relatively low concentrations and reveal stained structures in detail (for a review, see Cowden and Curtis, 1986). Yoshikami and Okun (1984) have recently shown that 2 fluorescent dyes that vitally stain mitochondria $\left(3,3^{\prime}\right.$-diethyloxadicarbocyanine iodide $\left[\mathrm{DiOC}_{2}(5)\right]$ and rhodamine 123) also label neuromuscular synapses in some species. At mammalian neuromuscular junctions, however, we found these dyes to be unsatisfactory.

\footnotetext{
Received June 10, 1986; revised Sept. 16, 1986; accepted Sept 25., 1986.

We thank C. Rovainen and P. Taghert for supplying muscles of lamprey and Manduca, M. Rich for the rhodamine-labeled bungarotoxin, and Pat Newton for skillful assistance. We are also grateful to C. J. Forehand, R. D. Hadley, W. D. Snider, and J. Voyvodic for helpful comments on the manuscript. This work was supported by NIH Grants NS 11699, 18629, and 20364; a Javits Center grant; grants from the Muscular Dystrophy Association; and a McKuight Research Development Award to J.W.L.

Correspondence should be addressed to Dr. Jeff W. Lichtman, Department of Anatomy and Neurobiology, Washington University School of Medicine, 660 South Euclid Avenue, St. Louis, MO 63110.

Copyright (C) 1987 Society for Neuroscience $0270-6474 / 87 / 041207-08 \$ 02.00 / 0$
}

$\mathrm{DiOC}_{2}(5)$ was not useful because of high background and inconsistency of staining; rhodamine 123 , despite a reasonable quality of staining, faded quickly and has been reported to have severe toxic effects on at least some classes of cells (Lampidis et al., 1984). Nonetheless, the results reported by Yoshikami and Okun (1984) suggested that a survey of other mitochondrial dyes might be worthwhile in order to find an effective, nontoxic stain for living nerve endings in mammals.

In the work we report here, the qualities of 18 cationic mitochondrial dyes were tested at the mouse neuromuscular junction. Several dyes of the styryl pyridinium family are remarkably good stains for motor nerve terminals; the best of these probes4-(4-diethylaminostyryl)- $N$-methylpyridinium iodide (4-Di-2ASP)-appears to be nontoxic, highly specific for neuromuscular junctions in various species, unusually resistant to bleaching, inexpensive, and easy to use. Thus, molecules such as 4-Di-2ASP should provide excellent reagents for the study of longterm changes at the neuromuscular junction (see accompanying paper).

Some of these results have been briefly reported (Lichtman ct al., 1986).

\section{Materials and Methods}

Dyes were purchased from the sources indicated in Table 1 and used without further purification. Unless otherwise noted, muscles were immersed for $3 \mathrm{~min}$ in a $10 \mu \mathrm{M}$ solution of the dyc (an appropriate physiological saline was used for staining neuromuscular junctions in each of the various species examined). This dye concentration was arbitrary and certainly higher than necessary for some of the dyes tested. The molarity of the staining solution was calculated according to the manufacturer's statement of purity. Various dyes were visualized with appropriate Leitz epi-illumination cubes, as indicated in Table 2 (I2 cube: exciting wavelength $450-490 \mathrm{~nm}$, suppression $515 \mathrm{~nm}$; N2 cube: 530 $560 \mathrm{~nm}$ excitation, $580 \mathrm{~nm}$ suppression; H2 cube: $390-490 \mathrm{~nm}$ excitation, $515 \mathrm{~nm}$ suppression). A conventional tungsten filament (Osram Xenophot; $100 \mathrm{~W}, 12 \mathrm{~V}$ ) was used as the source of illumination in all experiments; the illuminating light was passed through a BG38 heat filter. To obtain permanent records, the stained terminals were photographed with high-speed color film (Ektachrome 1600) using 25 or $50 \times$ water-immersion objectives with numerical apertures of 0.60 and 1.00 , respectively.

Sternomastoid or diaphragm muscles of young adult mice (CF1 strain; 22-32 gm) were chosen for routine staining tests and electrophysiological measurements. The sternomastoid was used because of its accessibility in the neck for in vivo studies (see accompanying paper). For electrophysiological studies, the muscles were maintained in lactated Ringer's solution (Travenol) at room temperature. Muscle fibers were impaled near their midportion with glass microelectrodes filled with 0.5 $\mathrm{M} \mathrm{KCl}$ (electrode resistances were 5-10 M ); miniature endplate potential amplitude and frequency were measured from a storage oscilloscope.

\section{Results}

Efficacy of the dyes tested

To compare various dyes, we stained isolated mouse diaphragm or sternomastoid muscles in vitro for $3 \mathrm{~min}$ by superfusion of 
Table 1. Alphabetical listing of the 18 mitochondrial dyes tested, their formula weights, structures, and the sources from which they were obtained

NAME OE DYE

FORMULA WEIGHT

STRUCTURE

Chemical FAMILY

SOURCE

ACRIDINE ORANGE 10-

514

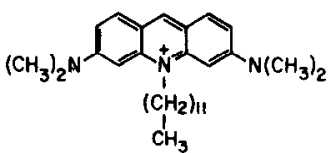

ACR I DINE

Molecular

DODECYL BROMIDE

Auramine 0

304

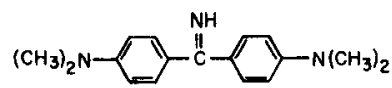

DI ARYLMETHANE

FISHER

2-(4-D IETHYLAMINOSTYRYL) -NMETHYLPYRIDINIUM IODIDE

4-(4-DIETHYLAMINOSTYRYL)-NMETHYLPYRIDINIUM IODIDE [4-DI-2-ASP]

\section{3,3' -D IETHYLOXADI CARBO- CYANINE IODIDE}

394

486<smiles></smiles><smiles>CN(C)c1ccc(CC=CC2=CC[N+](C)(C)C=C2)cc1</smiles>

PYRIDINIUM

PyridiniUM

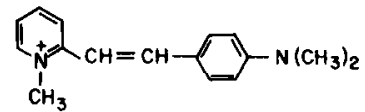

366

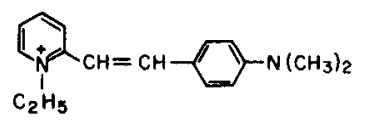

N-METHYLPYRIDINIUM IODIDE

4- (4-DIMETHYLAMINOSTYRYL) N-METHYLPYRIDINIUM IODIDE
380
PYRIDINIUM

PyridiniUm

Molecular PROBES

PYRIDINIUM

MOLECULAR PROBES

CYANINE

EASTMAN

MOLECULAR PROBES a $10 \mu \mathrm{M}$ dye solution. The efficacy of each dye was judged primarily according to its ability to make the nerve terminals visible relative to the background staining of muscle fibers; we also compared the persistence of staining during prolonged exposure $(5 \mathrm{~min})$ to exciting wavelengths at a standard intensity $(100 \mathrm{~W})$.

Only 3 of the 18 dyes tested showed no ability to stain mammalian motor nerve terminals under these conditions (Table 2). As the ranking in Table 2 indicates, no particular class of dyes was uniformly effective in staining nerve terminals. It was clear, however, that the most successful dyes tested were those of the styryl pyridinium family. The staining was reasonably good for all the dyes of this class, although they differed in quality and fastness to light. Taking staining quality and resistance to bleaching together, 4-Di-2-ASP was judged to be the most effective of these reagents. Therefore, more detailed studies were carried out using this dye.

Representative photomicrographs of nerve terminals in mouse sternomastoid muscles after a 3 min exposure to 4-Di-2-ASP are shown in Figure 1. Within $1 \mathrm{~min}$ of application, a $10 \mu \mathrm{M}$ solution of 4-Di-2-ASP stained virtually all endplates on superficial fibers. Initially, the nerve tcrminals appeared somewhat stippled, but by 3 min the staining was generally uniform and of maximum intensity. The dye was distributed throughout motor nerve terminals and only lightly stained preterminal motor axons. Transverse cryostat sections, after such brief exposures, showed that the staining was limited to endplates on superficial fibers. The intensity of staining began to fade within several minutes after washing out the dye, but terminals could still be faintly seen an hour later.

Continuous exposure to the exciting light, even for several minutes, had no obvious effect on the appearance of the stained endplates in mammalian muscle or on the rate of fading. Because light had only a modest effect on the rate of fading, the diminished intensity over time presumably represents washout of the dye. Terminals that had faded could be restained by repeating the procedure. 


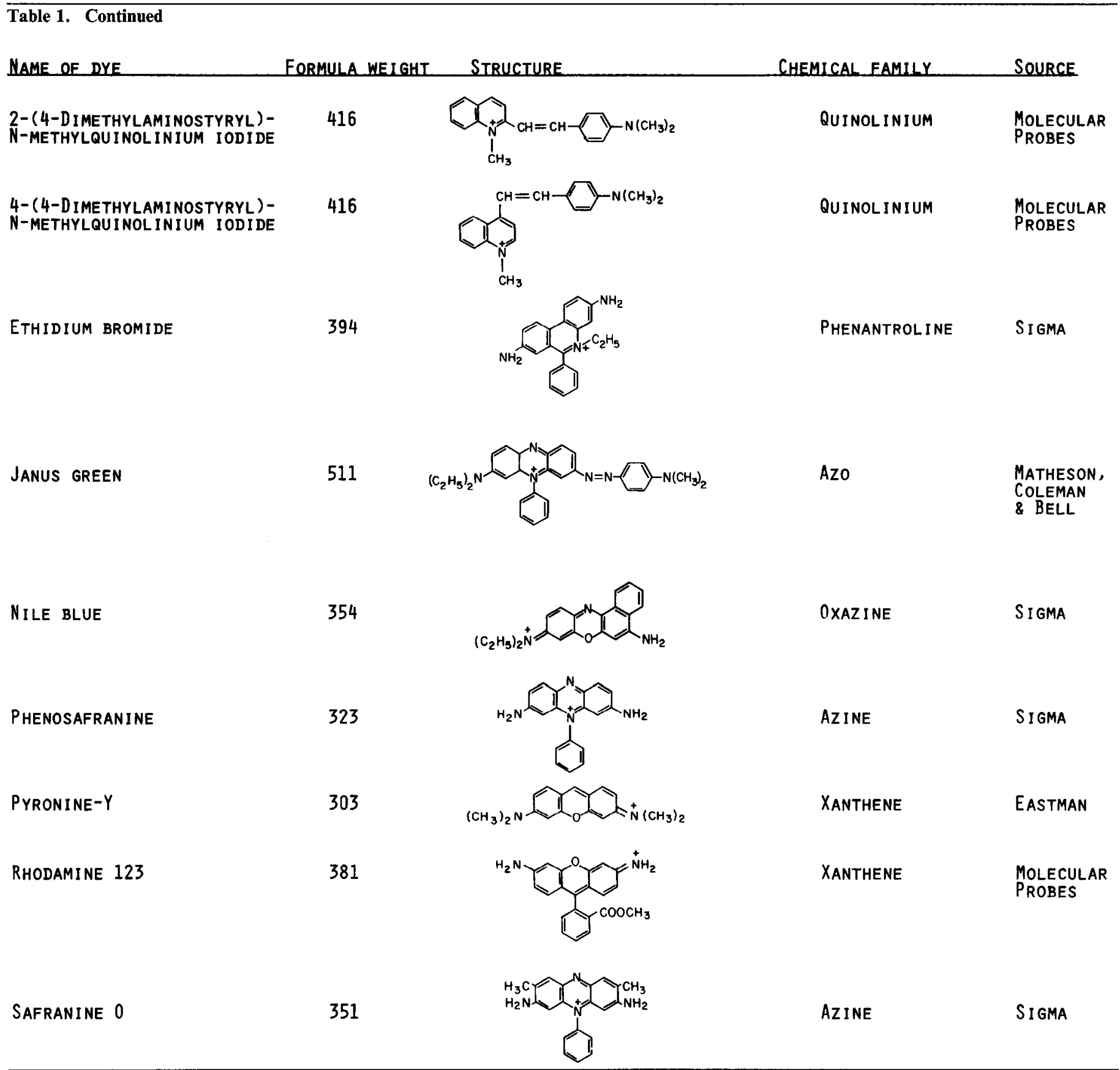

\section{Evidence that staining is presynaptic}

To ensure that 4-Di-2-ASP stained the presynaptic nerve terminals, sternomastoid muscles in 4 animals were completely denervated by nerve section $3-5 \mathrm{~d}$ before routine staining with 4-Di-2-ASP. Following nerve degeneration, stained terminals were no longer evident. We also labeled the postsynaptic receptors with rhodamine-conjugated $\alpha$-bungarotoxin at the time of 4-Di-2-ASP staining. In these doubly stained preparations, it was clear that 4-Di-2-ASP labeled presynaptic endings that were congruent with the rhodamine-labeled receptors (Fig. 2).

\section{Efficacy of 4-Di-2-ASP in different species}

To test the efficacy of the dye in various species, we used 4-Di2-ASP to stain terminals in muscles of several of the major vertebrate classes; we also tested the staining of insect muscle in which transmission is not cholinergic (see, for example, Hoyle, 1985). Motor nerve terminals were stained in skeletal muscles of all of the animals examined; these included frog (Rana pipiens; pectoral muscles), snake (Thamnophis sirtalis; transversus abdominis muscle), fish (Carassius auratus; abdominal muscles), lamprey (Petromyzon marinus; abdominal muscles), and moth (Manduca sexta larvae; body wall muscles). Examples of stained terminals from 2 vertebrate classes are shown in Figure 3. The staining of the larval insect muscle indicates that 4-Di-2-ASP is not specific for cholinergic terminals.

\section{Tests of the toxicity of 4-Di-2-ASP}

The toxicity of 4-Di-2-ASP was evaluated in mouse diaphragm by measuring miniature endplate potential amplitude and fre- 

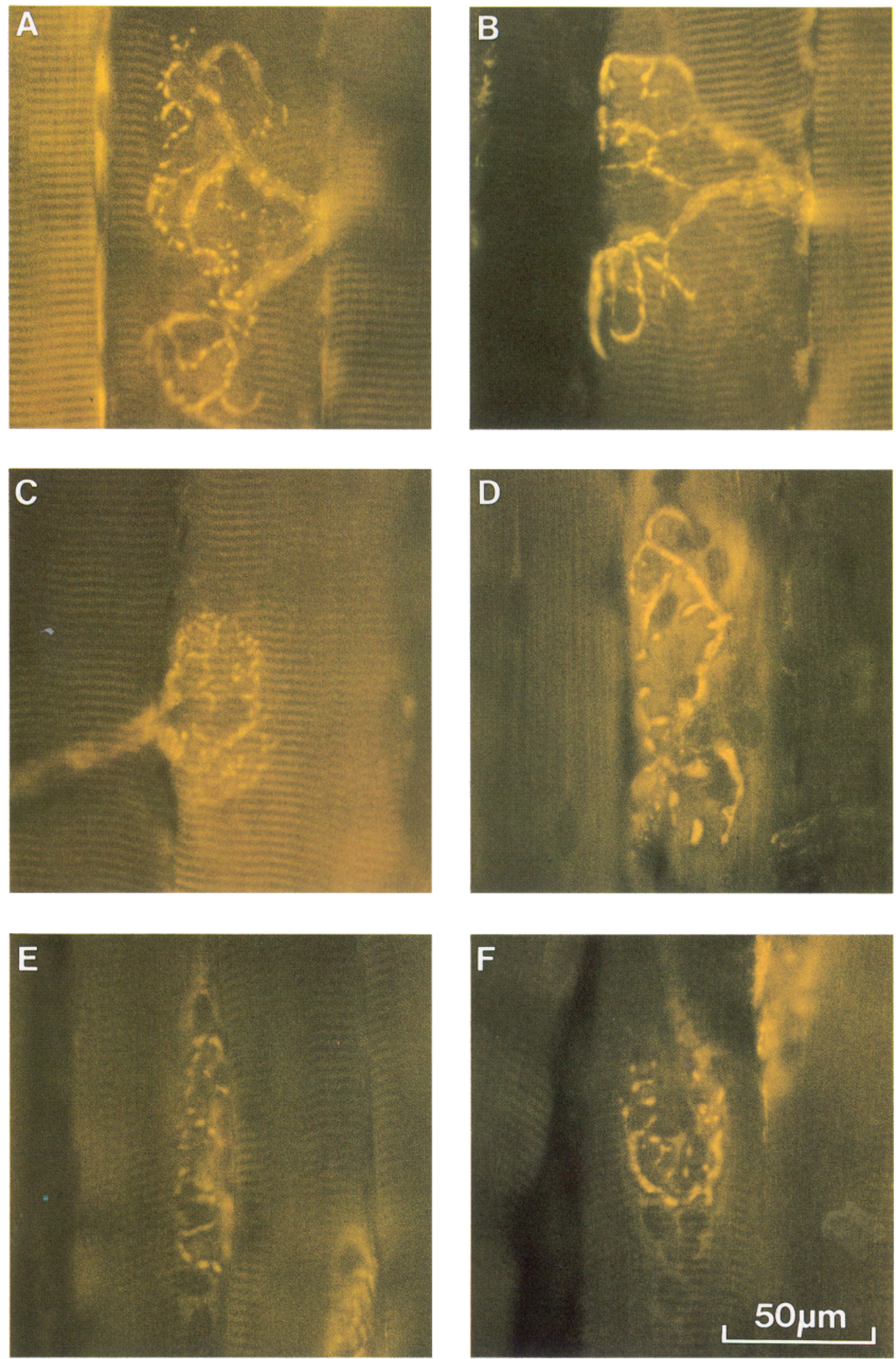

Figure 1. Examples of stained motor nerve terminals in the mouse sternomastoid muscle, using the most effective of the dyes listed in Table 24-Di-2-ASP. Muscles were stained with a $10 \mu \mathrm{M}$ solution for $3 \mathrm{~min}$ and the endplates then photographed using high-speed color film (Ektachrome $1600)$. The stained terminals in the figure are arranged in order of decreasing size and complexity $(A-F)$ to show the range of morphologies found among normal neuromuscular junctions in this mouse muscle. 


\begin{tabular}{|c|c|c|c|c|}
\hline Dye & $\begin{array}{l}\text { Excitation } \\
\text { and } \\
\text { emission }\end{array}$ & $\begin{array}{l}\text { Efficacy of } \\
\text { nerve termi- } \\
\text { nal staining } \\
\end{array}$ & $\begin{array}{l}\text { Fastness to } \\
\text { light }\end{array}$ & Consistency \\
\hline Acridine orange-10-iodecyl bromide & $\mathbf{H}_{2}$ & 0 & - & - \\
\hline Auramine $\mathrm{O}$ & $\mathbf{H}_{2}$ & 0 & - & - \\
\hline Nile blue & white light & 0 & - & - \\
\hline Ethidium bromide & $\mathrm{N}_{2}$ & + & + & Poor \\
\hline Janus green & $\mathrm{I}_{2}, \mathrm{~N}_{2}, \mathrm{H}_{2}$ & + & * & Poor \\
\hline $\begin{array}{l}\text { Phenosafranine } \\
\text { 2-(4-Dimethylaminostyryl)- }\end{array}$ & $\mathbf{I}_{2}, \mathrm{H}_{2}$ & + & ++ & Poor \\
\hline $\begin{array}{l}N \text {-methylpyridinium iodide } \\
\text { 2-(4-Dimethylaminostyryl)- }\end{array}$ & $\mathbf{I}_{2}, \mathrm{H}_{2}$ & ++ & ++ & Poor \\
\hline $\begin{array}{l}N \text {-methylquinolinium iodide } \\
\text { 4-(4-Dimethylaminostyryl)- }\end{array}$ & $\mathrm{N}_{2}$ & ++ & ++ & Poor \\
\hline $\begin{array}{r}N \text {-methylquinolinium iodide } \\
\text { 3,3'-Diethyloxadicarbocyanine }\end{array}$ & $\mathrm{N}_{2}$ & ++ & ++ & Poor \\
\hline $\begin{array}{l}\text { iodide } \\
\text { 4-(4-Dimethylaminophenyl)- } \\
\text { butadenyl- } N \text {-methylpyridinium }\end{array}$ & $\mathrm{I}_{2}, \mathrm{H}_{2}$ & ++ & ++ & Poor \\
\hline $\begin{array}{l}\text { iodide } \\
\text { 4-(4-Dimethylaminostyryl)- }\end{array}$ & $\mathrm{I}_{2}, \mathrm{H}_{2}$ & ++ & ++ & Poor \\
\hline $\begin{array}{l}N \text {-methylpyridinium iodide } \\
\text { 2-(4-Diethylaminostyryl)- }\end{array}$ & $\mathrm{I}_{2}, \mathrm{H}_{2}$ & ++ & ++ & Poor \\
\hline$N$-methylpyridinıum iodide & $\mathrm{I}_{2}, \mathrm{H}_{2}$ & $++(+)$ & +++ & Very good \\
\hline Pyronine-Y & $\mathrm{I}_{2}, \mathrm{~N}_{2}, \mathrm{H}_{2}$ & +++ & + & Fair \\
\hline Safranine O & $\mathrm{I}_{2}, \mathrm{H}_{2}$ & +++ & ++ & Good \\
\hline $\begin{array}{l}\text { Rhodamine } 123 \\
\text { 2-(4-Dimethylaminostyryl)- }\end{array}$ & $\mathrm{I}_{2}, \mathrm{H}_{2}$ & +++ & ++ & Good \\
\hline $\begin{array}{l}N \text {-ethylpyridinium iodide } \\
\text { 4-(4-Diethylaminostyryl)- } \\
N \text {-methylpyridinium iodide } \\
\text { (4-Di-2-ASP) }\end{array}$ & $\mathrm{I}_{2}, \mathrm{H}_{2}$ & ++++ & +++ & Very good \\
\hline
\end{tabular}

$\overline{\text { A } 10 \mu \mathrm{M} \text { solution of each dye was applied for } 3 \mathrm{~min} \text { at room temperature. The efficacy of nerve terminal staining was }}$ judged subjectively on a 0 to ++++ scale $(0=$ no staining, $++++=$ staining intensity achieved with the best of the dyes tested, 4-Di-2-ASP). Fastness was evaluated after $5 \mathrm{~min}$ of exposure to light (see text). Consistency refers to the uniformity of staining among the endplates within a muscle, and to the reproducibility of staining in different experiments.

* The intensity of staining was increased by light.

quency. High concentrations of 4-Di-2-ASP (1 mM) completely abolished spontaneous miniature endplate potential activity in surface fibers within a minute of application. However, when the dye was washed out, miniature endplate potentials promptly reappeared and gradually regained their full amplitude over 1$2 \mathrm{hr}$ (Fig. 4). Lower concentrations of 4-Di-2-ASP (15-50 $\mu \mathrm{M})$ reduced the amplitude of the miniatures without abolishing them; this effect was readily reversed when the dye was washed out. Little or no effect on miniature endplate potentials was apparent at the concentration used for routine staining $(10 \mu \mathrm{M})$. There were no obvious effects on miniature frequency at any of the concentrations tested. Moreover, during these experiments the membrane potential of the muscle fibers remained unchanged. Thus 4-Di-2-ASP behaves like a weak blocker of cholinergic receptors; the rapid reversibility of this effect, even at high concentrations, suggests that the dye does not cause any lasting changes in synaptic mechanisms.

Because light can enhance the toxic effects of many reagents, we also assessed the electrophysiological consequences of illumination during staining. Miniature endplate amplitude and frequency after staining with a $10 \mu \mathrm{M}$ solution of 4-Di-2-ASP were monitored for $20 \mathrm{~min}$ while the muscle was illuminated with high-intensity white light (150 W source). Sustained illumination had no obvious effect on these parameters. We therefore conclude that 4-Di-2-ASP, at the concentration routinely used, is a remarkably nontoxic stain, even when strongly illuminated. This conclusion is substantiated by the long-term studies of terminal structure reported in the accompanying paper (Lichtman et al., 1987).

\section{Discussion}

Armstrong et al. (1956) were among the first workers to suggest that mitochondrial stains can be used to demonstrate nerve terminals. More recently, Yoshikami and Okun (1984) used the mitochondrial dyes rhodamine 123 and $\mathrm{DiOC}_{2}(5)$ to stain the presynaptic portion of living neuromuscular junctions in frogs (see also Kelly et al., 1985). However, various untoward effects of these and other mitochondrial dyes have been reported. For instance, mitochondrial respiration was depressed by some of the fluorescent mitochondrial dyes, even when applied at micro- 


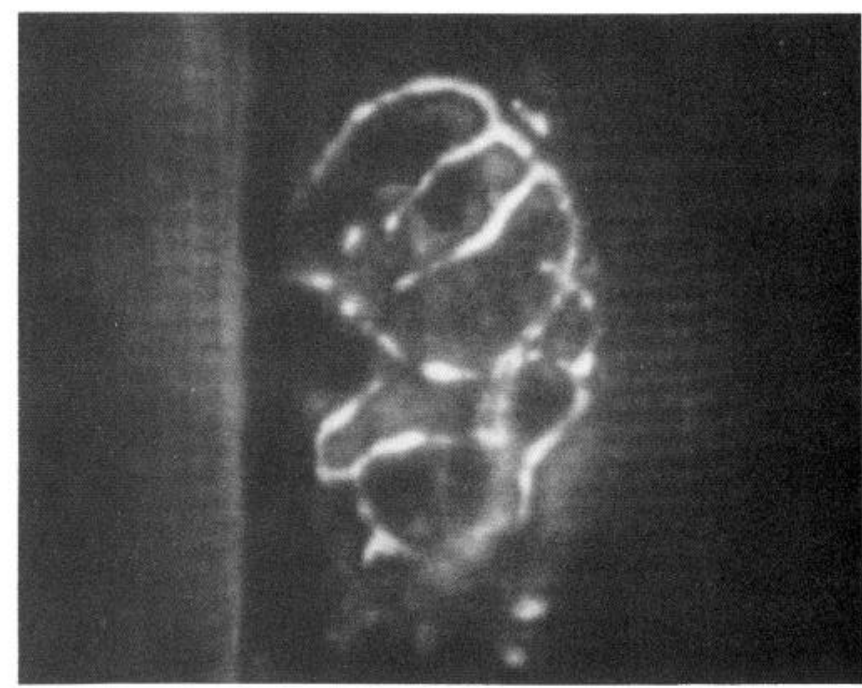

4-Di-2-Asp

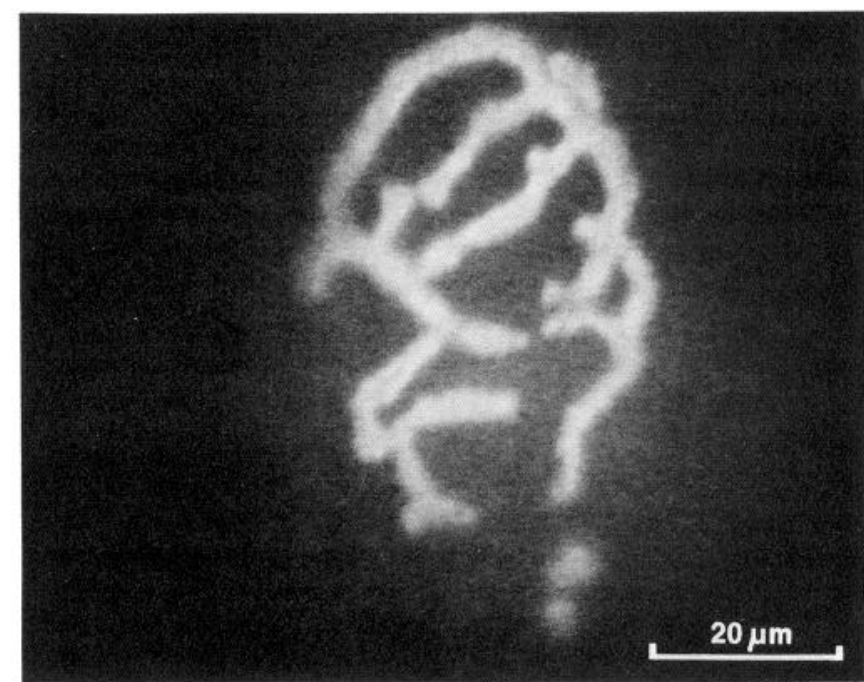

Rhodamine $\alpha$-bungarotoxin

Figure 2. A mouse neuromuscular junction stained concurrently with rhodamine $\alpha$-bungarotoxin and 4-Di-2-ASP. Mouse sternomastoid muscle was incubated in situ for $5 \mathrm{~min}$ (see the accompanying paper for details) with a solution of rhodamine $\alpha$-bungarotoxin in saline; the endplate was photographed from a video monitor using optics appropriate for visualizing rhodamine. The preparation was subsequently counterstained with a $10 \mu \mathrm{M}$ solution of 4-Di-2-ASP for $3 \mathrm{~min}$. The same endplate was then rephotographed with fluorescein optics. The elements stained with 4-Di-2ASP (left) overlie (and are within) the rhodamine-labeled receptor sites (right).
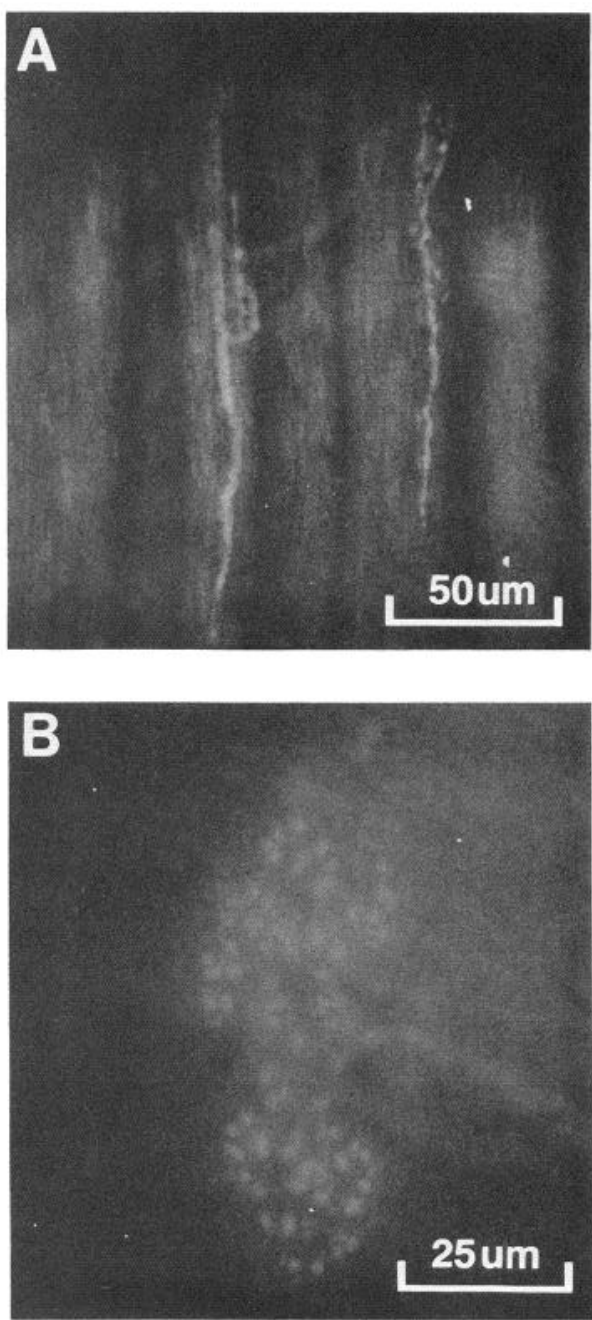

molar concentrations (see, for example, Mai and Allison, 1983). Moreover, cationic rhodamines affected the function and viability of mammalian myocardial cells in culture (Lampidis et al., 1984) and inhibited oxidative phosphorylation (Gear, 1974; Mai and Allison, 1983).

On the other hand, studies of the effects of styryl pyridinium dyes on cultured amphibian myocardial cells (Bereiter-Hahn, 1976), mammalian brown fat (Rafael and Nicholls, 1984), and mammalian renal epithelial cells (Horster et al., 1983) did not reveal any obvious damage. Stained cells continued to grow in culture after dye uptake, and protozoan motility was unaffected by a $24 \mathrm{hr}$ exposure to a styryl pyridinium dye very similar to the reagent we studied in detail (4-Di-2-ASP) (Morozova et al., 1981; Miyakawa et al., 1984). Furthermore, 4-Di-2-ASP did not cause any morphological change of stained nerve terminals, even over periods of many days (see Lichtman et al., 1987). The only obvious effect of this dye on the mammalian neuromuscular junction was a reversible depression of synaptic transmission at concentrations higher than those we routinely used for staining. This apparent interaction of the dye with acetylcholine receptors may have been related to the quaternary nitrogen atom in the pyridinium ring (see, for example, Bovet, 1972). Styryl pyridinium compounds also show reversible, noncompetitive inhibition of choline acetyltransferase in vitro and, to a lesser degree, of acetylcholinesterase (see Cavallito et al., 1970). However, these pharmacological actions are minimal in vivo, even for the most potent of these compounds (Aquilonius et al., 1971; MacIntosh and Collier, 1976).

Figure 3. Nerve terminal staining with 4-Di-2-ASP in amphibians and reptiles. A, Terminals in frog (Rania pipiens) cutaneous pectoris muscle. $B$, Motor terminal in the garter snake transversus abdominis muscle. The method of staining in these animals was the same as that used in mouse; the dye stained neuromuscular junctions satisfactorily in all of the species tested (see text). 


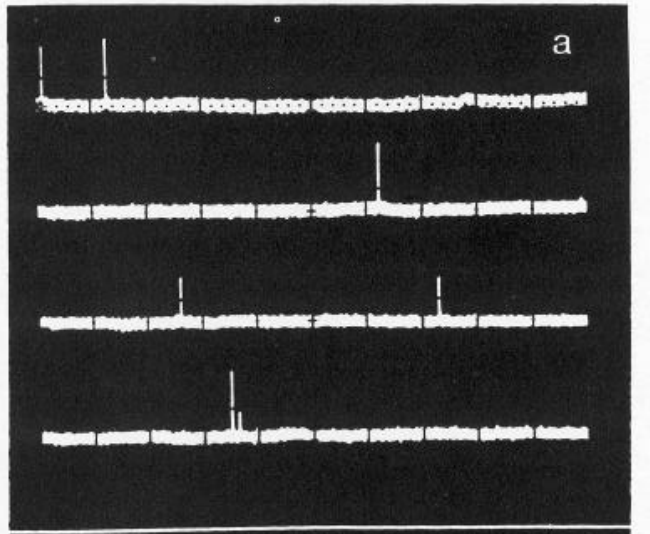

b

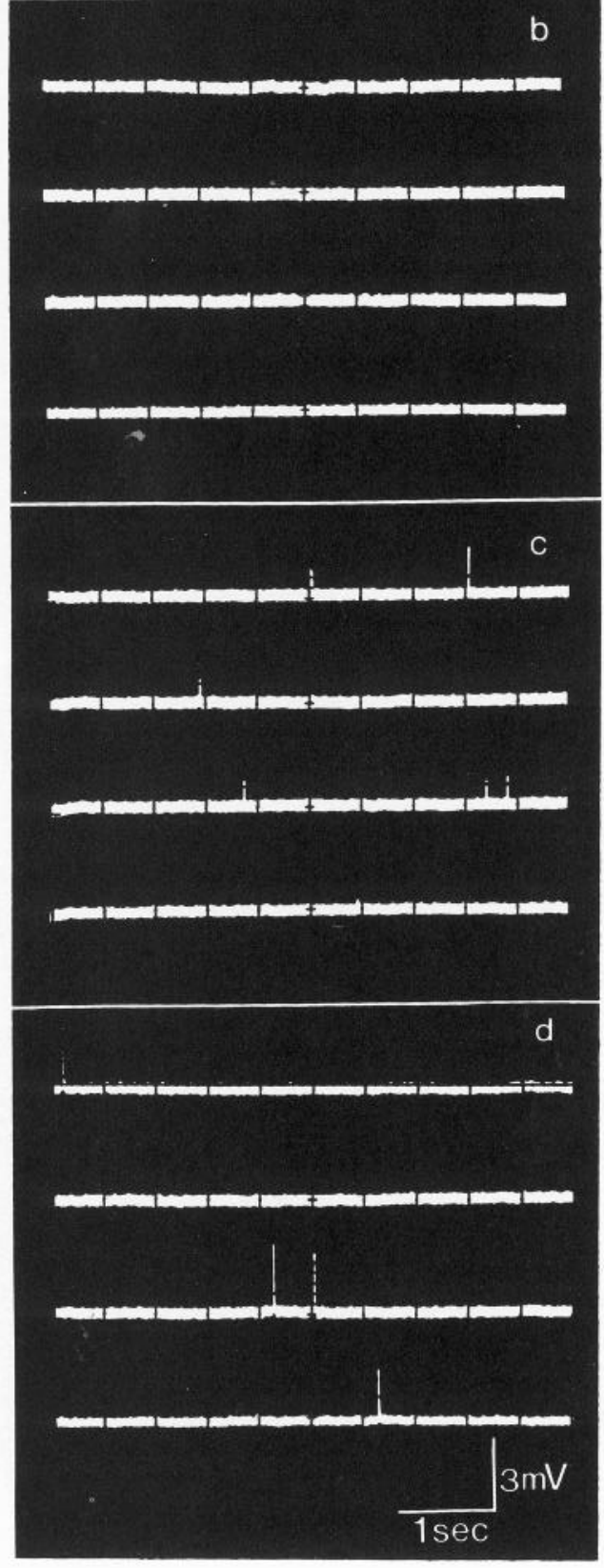

Figure 4. Intracellular recordings of miniature endplate potentials in the mouse diaphragm before $(a)$, during $(b)$, and after $(c, d)$ staining with a high concentration of 4-Di-2-ASP. The electrode remained in the same fiber throughout the experiment. The muscle was initially superfused with Ringer's solution at room temperature $(a)$. Within a few seconds
(Aquilonius et al., 1971; MacIntosh and Collier, 1976).

We do not know the mechanism of terminal staining by the styryl pyridinium dyes. Muscles removed from mice and allowed to stand for an hour in saline before staining generally gave poor results. Furthermore, fixation quickly abolished terminal staining. These observations imply that staining depends on some aspect of the normal metabolism of nerve terminals. The uniformity and intensity of staining with 4-Di-2-ASP argues against an effect based solely on mitochondrial staining.

A number of neurobiological issues could be addressed if other axon terminals in the peripheral and central nervous system could be visualized over time. Certainly, the styryl pyridinium dyes are effective in staining neuromuscular junctions in a variety of species. Preliminary examination of staining elsewhere in the mammalian nervous system has shown that the dye 4-Di-2-ASP effectively stains nerve fibers and terminals in the cornea and the gut. This reagent is ineffective, however, in staining synaptic boutons in autonomic ganglia and smooth muscle when applied locally. On the other hand, systemic administration of some styryl pyridinium dyes vitally stains boutons on autonomic ganglion cells (Purves et al., 1986). Finally, styryl pyridinium dyes have also been used as potential sensitive probes (see, for example, Loew et al., 1985). If the dyes that stain presynaptic terminals respond to membrane voltage, it may be possible to study the activity of specific terminals.

In summary, a number of cationic mitochondrial dyes stain motor nerve terminals in living animals. The most effective of the agents that we examined was a molecule of the styryl pyridinium family, 4-Di-2-ASP; a variety of tests show that this agent has little or no toxicity for motor nerve terminals. As is demonstrated in the accompanying paper (Lichtman et al., 1987), 4-Di-2-ASP can be used to follow the structure of identified neuromuscular junctions over arbitrarily long intervals.

\section{References}

Aquilonius, S. M., L. Frankenberg, K.-E. Stensio, and B. Winbladh (1971) In vivo studies of two choline acetyltranferase inhibitors. Acta Pharmacol. Toxicol. 30: 129-140.

Armstrong, J., K. C. Richardson, and J. Z. Young (1956) Staining neural end feet and mitochondria after post-chroming and carbowax embedding. Stain Technol. 31: 263-271.

Bereiter-Hahn, J. (1976) Dimethyl-aminostyryl-methylpyridiniumiodide (DASPMI) as a fluorescent probe for mitochondria in situ. Biochim. Biophys. Acta 423: 1-14.

Bovet, D. (1972) Synthetic inhibitors of neuromuscular transmission: Chemical structures and structure-activity relationships. In International Encylcopedia of Pharmacology and Therapeutics, Vol. 1, C. Raduoco-Thomas, ed., pp. 243-294, Pergamon, Oxford.

Cavallito, C. J., H. L. White, H. S. Yun, and F. F. Foldes (1970) Inhibitors of choline acetyltransferase. In Drugs and Cholinergic Mechanisms in the CNS, E. Heilbrown and A. Winter, eds., pp. 97116, Försvarets Forskningsanstalt, Stockholm.

\section{$\leftarrow$}

of the application of a $1 \mathrm{~mm}$ solution of 4-Di-2-ASP (a concentration 100 times greater than we routinely used), miniature endplate potentials were abolished $(b)$. Several minutes after application of the dye, washout was begun; 5 min later, the miniatures were again visible, but their amplitudes were small $(c)$. Over the next $100 \mathrm{~min}$, the size of the miniatures gradually returned to normal $(d)$. The membrane potential of the muscle fiber $(-76 \mathrm{mV})$ and the miniature frequency remained approximately the same throughout the experiment. The observed frequency of miniature endplate potentials is usual for these recording conditions. Little or no effect of the dye on miniature endplate potentials was noted at the concentration of dye used for routine staining $(10 \mu \mathrm{M})$. 
Coers, C., and A. L. Woolf (1959) The Innervation of Muscle, Blackwell, Oxford.

Cowden, R. R., and S. K. Curtis (1986) In vitro (supravital) fluorescence cytochemistry. Bas. Appl. Histochem. 30: 7-40.

Gear, A. R. L. (1974) Rhodamine GG, a potent inhibitor of mitochondrial oxidative phosphorylation. J. Biol. Chem. 249: 3628-3637.

Horster, M. F., P. D. Wilson, and H. Gundlach (1983) Direct evaluation of fluorescence in single renal epithelial cells using a mitochondrial probe (DASPMI). J. Microsc. 132: 143-148.

Hoyle, G. (1985) Muscles and Their Neural Control, Wiley, New York.

Kelly, S. S., N. Amls, and N. Robbins (1985) Fluorescent staining of living mouse neuromuscular junctions. Pflügers Arch. 404: 97-99.

Lampidis, T. J., C. Salet, G. Moreno, and L. B. Chen (1984) Effects of the mitochondrial probe rhodamine 123 and related analogs on the function and viability of pulsating myocardial cells in culture. Agents Actions 44: 751-757.

Lichtman, J. W., L. Magrassi, and D. Purves (1986) Visualization of motor ncrve terminals over time in living mice. Soc. Neurosci. Abstr. 12: 390 .

Lichtman, J. W., L. Magrassi, and D. Purves (1987) Visualization of neuromuscular junctions over periods of several months in living mice. J. Neurosci. 7: 1215-1222.

Loew, L. M., L. B. Cohen, B. M. Salzberg, A. L. Obaid, and F. Bezanilla (1985) Charge-shift probes of membrane potential. Characterization of amino-styrylpyridinium dyes in the squid giant axon. Biophys. J. 47: 71-77.

MacIntosh, F. C., and B. Collier (1976) Neurochemistry of cholinergic terminals. In Handbook of Experimental Pharmacology, Vol. 42, E. Zaimis, ed., pp. 99-228, Springer-Verlag, Berlin.
Mai, M. S., and W. S. Allison (1983) Inhibition of an oligomycinsensitive ATPase by cationic dyes, some of which are atypical uncouplers of intact mitochondria. Arch. Biochem. Biophys. 221: 467476.

McMahan, U. J., and S. W. Kuffler (1971) Visual identification of synaptic boutons on living ganglion cells and of varicosities in postganglionic axons in the heart of the frog. Proc. R. Soc. Lond. [Biol.] I77: 485-488.

Miyakawa, I., M. Aoi, N. Sando, and T. Kokoiwa (1984) Fluorescence microscopic studies of mitochondrial nucleotides during meiosis and sporulation in the yeast Saccharomyces cerevisiae. J. Cell Sci. 66: 2138.

Morozova, G. I., G. E. Dobretsov, G. Duburs, R. Duburs, V. M. Golitsyn, G. M. Barenboim, Y. A. Vladimirov (1981) Fluorescence of 4-( $p$-dimethylaminostyryl)-1-methylpyridinium in the living cell. Tsitologiya 23: 916-923.

Polyak, S. (1941) The Retina, U. Chicago P., Chicago.

Purves, D., and J. W. Lichtman (1987) Synaptic sites on reinnervated nerve cells visualized at two different times in living mice. J. Neurosci. (in press).

Purves, D., H. Yawo, and J. Voyvodic (1986) Systemic administration of a fluorescent dye visualizes nerve terminals in a mammalian autonomic ganglion. Soc. Neurosci. Abstr. 12: 390.

Rafael, J., and D. G. Nicholls (1984) Mitochondrial membrane potential monitored in situ within isolated guinea pig brown adipocytes by a styryl pyridinium fluorescent indicator. FEBS Lett. 170: 181185.

Yoshikami, D., and L. Okun (1984) Staining of living presynaptic nerve terminals with selective fluorescent dyes. Nature 310: 53-56. 